\title{
Mediating High Conflict Matters
}

\section{Tony Whatling}

\section{Abstract}

To what extent is practice and training adapting to meet the challenge of an increase in high conflict levels in dispute resolution - including developments in social media and electronic communications?

This article explores recent changes in disputants' conflict behaviour, together with potential implications for practitioner skills, strategies, values and training. It will provide some theoretical frameworks related to conflict behaviour and conflict ideologies that can be applied to practice. Recent developments in electronic and social mass media communications are explored, together with the impact these have had on conflict patterns in dispute resolution. It considers the extent to which developments in conflict behaviour may need to be challenged more overtly by mediators, for example through a more pro-active mentoring dialogue, including in individual pre- mediation meetings. Finally, it offers some recommendations as to how such challenges and ideas for change, can be utilised in a way that does not impair the quality of the client mediator relationship.

\section{Keywords}

Meditation, conflict, mentoring, development

\section{Introduction}

"The past is another country they do things differently there" (Hartley). This article:

- Explores the extent to which patterns of conflict behaviour by clients in mediation has been changing over time, and how far alternative dispute resolution (ADR) practitioners and training, are adapting to such changes.

- Provides some theoretical frameworks related to conflict behaviour and conflict ideologies that can be applied to practice.

- Explores recent developments in electronic and social mass media communications and the impact these have had on conflictbehaviour.

- Considers the extent to which recent conflict behaviours may need to be challenged more overtly by mediators, through a more pro-active mentoring dialogue.

- Finally, it offers some recommendations as to how such challenges and ideas for change, can be utilised in a way that does not impair the quality of the client mediator relationship. 
Anecdotal evidence from mediation practitioners indicates that the conflict behaviour of mediation clients has changed significantly over the past few years. Increasingly, disputants come with learned styles of conflict resolution significantly different to those previously encountered by mediation practitioners.

This evidence has been gathered by the author in the UK over the past two years, working in the family mediation context, from a combination of regular supervision meetings with practitioners, as professional practice consultant (PPC) and regional PPC support group meetings. The author has also provided two continuing professional development (CPD) workshops on this topic at the request of practitioners, and co-presented two workshops at the college of mediators (COM) annual conference at Loughborough university in 2016.

Over the decades of development in mediation a recurring debate relates to the extent to which it should include dealing with emotion. One writer describes emotions as:

Both a cause and escalator of conflict, and positive feelings among the parties are often a key component of resolution. Once one accepts that emotion is the foundation of all conflict, the issue of how emotion influences the management of conflict becomes central. Many theorists have begun to point out that the lack of detailed attention paid to emotions and their role in relationships limits our understanding of conflict and that more work needs to be done to remedy this ... Often trying to suppress or dampen the emotions may simply lead to resentment and the breakdown of agreements. Parties may try to disrupt the process because they do not feel heard, or refuse to follow through with an agreement because their feelings were not recognized ... Feelings that may dissuade parties from agreeing to a negotiated settlement that appears in all other respects to be reasonable include distrust, anger, fear, contempt, embarrassment, shame, pride and disappointment. As a result of negative feelings, one party may be antagonistic and resist anything the other party proposes. Helping parties to communicate and acknowledge their emotions is key to the restoration of healthy relationships (Maiese, 2005:1).

\section{Conflict Ideologies and life-scripts}

We have all evolved personal 'life-scripts' about conflict. Depending on our childhood experiences, we may have come to regard conflict as potentially exciting, creative, energising and positive. Alternatively, we may see it as worrying, potentially painful and essentially negative.

This notion of 'life-scripts' is usefully amplified by other writers:

Our analysis of mediation - as a form of conflict discourse shaped by ideology - is grounded on two premises derived from recent studies of the construction and representation of ideology in everyday discourse. The first premise is that "ideologies" are organising frameworks that people use to view, interpret, and judge their surrounding world. Although ideologies are often 
held as cognitive values or expectations, they are acquired and expressed through social phenomena; people learn (and recreate) ideologies through participation in groups and relationships (Billing, 1988 cited in Folger and Jones, 1994: 7).

As well as developing individual conflict ideologies, people are substantially influenced by absorbed cultural ideologies. Mediators also acquire professional conflict ideologies. This triadic influence needs to be understood if practitioners are to develop the essential capacity to both 'listen and think' outside of their personal, cultural and professional conflict ideologyboxes.

One particular useful contemporary label for this capacity is 'Cultural fluency'.

Cultural fluency arises from knowing something about the lenses that we look through and then learning from the surprises we encounter as we come to glimpse the world through others' lenses. In this way we begin to anticipate, internalise, express and navigate in unfamiliar systems (LeBaron and Pillay, 2006: 58).

\section{Gaining clients' co-operation by understanding their conflict styles}

Ideally this work is done pre-mediation, with each client seen separately. During that time valuable information can be gathered from each disputant regarding their particular conflict patterns and ideology. Clients are likely to be aware of what upsets and angers them, and how they tend to react when that happens. For example, they may use such metaphors as: when x happens I usually kick off, blow a fuse, freak out, and go ballistic.

Open-ended questions can be used strategically, so as to build up an understanding of how such metaphorical terms translate into actions and consequences. For example, a mediator might ask:

- What sort of things happen to cause you to kick off?

- Can you give me an example of how you might be feeling inside when that happens?

- If it came to any similar upset or argument in mediation, how do you think you might react, and how might I recognise that it was happening to you?

Once such 'cause-and-effect' consequences are more concretely identified, the discourse can progress to questions about what might help the individual and other parties involved to maintain the conflict at a constructive level.

On the issue of pre-mediation work with each party separately, others have also referred to the benefits of the separate meeting.

In our experience, it is in these separate meetings that a lot of the major work of the mediation is done. In these meetings, the mediator works carefully with each of the parties to construct a frame of meaning around the problem issue ... We are thinking mainly of situations where there are entrenched disputes that make it difficult for the parties to talk freely in front of each other (Winslade and Monk 2001:137). 
From this model of separate meetings, each party has the benefit of uninterrupted space and time. The mediator is in turn able to give the speaker 'free attention' and active empathic listening, free also from any risk of the other party interpreting verbal or non-verbal mediator responses as possible evidence of partiality.

"If you talk to a man in a language he understands, that goes to his head. If you talk to him in his language, that goes to his heart" (Nelson Mandela).

\section{Neurolinguistics and personal constructs}

The Concise Oxford English Dictionary defines neurolinguistics as the branch of linguistics concerned with the relationship between language and the brain. At its simplest, the theory posits the idea that all humans develop personal perceptions of reality, or what can be termed 'mental constructs', that are in turn reflected in the particular words they use. Applying such concepts to mediation practice suggests that there may be benefits in listening very carefully to particular words used by clients, so as to begin to comprehend their deeper meaning. Where the words relate to the more powerful emotions encapsulated in their stories, the mediator can usefully adopt the same words in their reflective responses. In doing so, the aim is to demonstrate a concern to stay true to the clients' internal frames of reference. As an example of this technique, in a community, workplace or family dispute, one party may refer to a stage when ... it all goes ballistic again, and the other may respond with ... yes and then you just lose the plot and end up walking away again.

The mediator can adopt these frames of reference and use the same words, both in reflective summaries, and when referring to the disputants' potential options for the future. So with the above example we might say: "From what you are each saying, it sounds like it might be really helpful right now if you could each think about what you need, and what else could be done differently, so as to avoid things going ballistic, or anyone losing the plot and walking out. Perhaps at least for the next few weeks or months, because it sounds like it's hard to get anything sorted between you when that happens". The idea is that the constructs embedded in the language used have important symbolic meaning for each individual.

\section{Bear baiting and medieval barbarism revisited}

For one contemporary example of sociological and generational changes in conflict behaviour, consider the potential modelling effect of the Jeremy Kyle show, which has been variously described as follows:

Many people love The Jeremy Kyle Show. With a consistent audience of about 1.5 million it has been a staple of the ITV daytime schedule for almost a decade. Younger viewers, in particular, seem to find the presenter addictive. You can buy T-shirts with slogans such as, Don't mess with

Jezza. One of the most damning critiques of Kyle show was made by a Manchester judge, Alan 
Berg, in 2007 when he sentenced a man to a $£ 300$ fine for headbutting a fellow guest on the programme: It is for no more and no less than titillating members of the public who have nothing better to do with their mornings than sit and watch this show, which is a human form of bear-baiting which goes under the guise of entertainment. Each show consists of very rough people trying to sort out their love lives etc. Who cares? I'm sure they can do it amongst themselves instead of sharing it with others. A lot of the guests start fighting anyway, which is why there are bouncers on set. The Jeremy Kyle show does serve at least one purpose; to show how aspects of Britain have declined in certain areas of our biggest towns and cities to the state of medieval barbarism (Burrell, 2013).

These dispute resolution influences, together with the impact of contemporary technological communications such as email and texting, may well support the hypothesis underpinning this article.

These technological communication advances may seem a relatively recent phenomenon. However, it is interesting to note that as far back as 1998, Deborah Tannen was writing about it, in a chapter entitled 'Fast forward': Technologically Enhanced Aggression'. Under such sub-headings as 'E-Mail Aggravates Aggression' and 'One-way Communication Breeds Contempt' she highlights such issues as:

E-mail and now the internet and the World Wide Web, are creating networks of human connection unthinkable even a few years ago. But at the same time that technologically enhanced communication enable previously impossible loving contact, it also enhances hostile and distressing communication ... As the ease of using the internet has resulted in more and more people logging on and sending messages to more and more others with whom they have a connection, it has also led to increased communication with strangers and this has resulted in 'flaming': vituperative messages that verbally attack (Tannen, 1998: 245-246).

Mediators practicing in the workplace context have also noted a significant increase in disputes resulting from this technological communication revolution. Tannen also noted this almost two decades ago:

In my research on workplace communication, I found that a large percentage of serious conflicts had been sparked by one-way communication such as memos, voice mail and e-mail (Tannen, 1998: 248).

The author concludes the chapter with:

The rising level of public aggression in our society seems directly related to the increasing isolation in our lives ... This isolation and the technology that enhances it is an ingredient in the argument culture. We seem to be better able at developing technological means of communication than at finding ways to temper the hostility that sometimes accompanies them (Tannen, 1998: 262). 
Typically, each of the parties in dispute has developed a personal idiosyncratic history of the minute details of the dispute. That historical record usually identifies itself as the victim, the trustworthy truth-sayer, and reasonable, rational party. Inevitably, the other party will be described as the antithesis of all those epithets. The longer the dispute has gone on the more this history will have been embroidered and will include negative 'add-ons', to add weight to the alleged bad behaviour of the other party. This familiar story-weaving usually includes additional negative attributions regarding the other party, provided by the 'Greek chorus' of family and friends.

Most mediators understand the importance of allowing these stories to be narrated, heard and understood, in the initial assessment meeting and early stages of joint meetings. Its importance is understood as natural, inevitable and cathartic whilst emphasising dispute resolvers' commitment to this cathartic benefit. One writer usefully draws attention to thisphenomenon:

I would suggest that we need to re-think this storytelling process when it involves one or more parties with high conflict personalities. People with high-conflict personalities (HCP's) tend to be preoccupied with the past defending their own behaviour (which is often a significant part of the problem). Ironically giving them an uninterrupted opportunity to tell their stories reinforces staying in the past and avoiding responsibility for the future whether the story is about what happened yesterday, last month or years ago ... some HCP's seem to get a high from telling their stories, just as addicts get a high from telling stories of their past experiences using drugs ... The stories also tend to place $100 \%$ of the responsibility on others especially the other party or parties to the dispute ... by the end of the story they hope that you will be persuaded:

- That they are totally not responsible for the problem or the solution.

- That the other party is totally the source of the problem.

- That you are the only one who can help them.

The result of hearing this intense storytelling is that you, as the dispute resolver, feel stressed, angry and/or helpless, and eager to get the case over with to relieve your frustration (Eddy, 2013: 3).

Assuming that the practitioner's initial intake assessment reveals this potential HCP syndrome in one or more parties, Eddy goes on to give four particular key suggestions for shifting the emphasis onto future problem-solving as follows:

- Structure the Process for Problem-Solving. From the start of the dispute resolution process, tell the parties that the emphasis will be on future problem solving.

- Avoid Getting Emotionally Hooked. Instead, respond with interest. It helps to give them EAR Statements which show empathy, attention and respect - without joining in their emotions or point of view.

- Ask for Proposals. One of the easiest methods of shifting the focus away from storytelling and onto 
future problem-solving is to ask the speaker: "Then what do you propose?"

- Consider Coaching Before Decision-Making. It can also be a time when you can hear their story and provide Empathy, Attention and Respect ... Then you can teach the party about how the dispute resolution process will go and their role in focusing on the future. That way you have heard enough storytelling to bond with. HCP's always feel like victims (and many have been at one time), but we don't help them to allow them to hear their own stories over and over again. Let's teach problem-solving in a respectful way by guiding them to learn that they can move forward - and helping them to do it with a sense of success that they can own (Eddy, 2013: 1-6).

\section{So what?}

As well as a good reflective question for mediators themselves as they formulate a potential hypothesis, this can also be a valid question to put to the parties directly. A typical example of such a question would be: So what are the implications of what just happened here in the room, or of what one party just said, or did? The question might usefully be extended to include - and in what way does what was said and done, influence what we are all attempting to do here in mediation?

Anyone can become angry, that is easy, but to be angry with the right person at the right time, and for the right purpose and in the right way, that is not within everyone's power and that is not easy (Aristotle).

\section{How goes pre-mediation is how goes the mediation - mentoring matters}

Pre-mediation assessments in high conflict cases will inevitably raise questions and concerns regarding time and funding resources. However, it may well be that time spent on such activity will actually speed up and enhance the negotiation process, so may well not actually involve greater time or cost. It may also have a beneficial impact on conversion to mediation and/or reduce drop-out rates.

This approach may also involve difficult, challenging and straight-talking conversations about the practitioners' perceptions of client' suitability for joint meetings. Such conversations will only be effective if the practitioner has earned the respect of each client throughout the first meeting. This respect is earned through demonstrable, unconditional, positive regard, non-judgemental responsiveness and empathic accurate listening, together with validation of the client's perception of the history.

Assuming that this 'nettle grasping 'phase of challenging conversations goes well, what are some of the options for mentoring? One option is to propose that all the parties involved might consider committing to a list of 'constructive negotiating principles', an example of which follows.

\section{Principles that help make mediation a constructive process}

Mediation works best when all those involved in the meetings:

1. Take turns to speak and do not interrupt each other.

2. Call each other by first names, not "he" or "she" or indeed more pejorative labels.

3. Use 'I' statements - for example not "he/she is always letting me down and hurting me" but 
"I feel hurt and let down when ... happens".

4. Try to describe what they want, rather than what they don't want i.e. what they would like other people to do differently in future, rather than what they don't want them to do, or to stop doing.

5. Try to avoid blaming or attacking others, or engage in put-downs and instead, to ask questions of each other for the purposes of clarifying and understanding them.

6. Try to avoid making rigid demands or taking fixed positions and instead, express themselves in terms of their personal needs and interests and the outcomes that they wish to achieve.

7. Listen carefully when any one person is speaking to them and avoids interrupting.

8. Listen carefully and with an open-mind, with the intention of trying to understand the other person's needs and interests.

9. Recognise that, even if they do not agree with each other, each person is entitled to their own views and perspective.

10. Try to avoid dwelling on things that did not work in the past, or what people did wrongly, but instead try to focus on how they would like things to be done differently in the future.

11. Attempt to avoid unproductive arguing, or expressing high emotion about the past history, and try instead to use the time in mediation to work toward the fairest and most constructive agreement possible.

12. Are able to speak up if they feel that something about the mediation process or meeting is not working for them.

13. Express their concerns if they feel the mediator is not being impartial or even-handed.

14. Feel able to ask to take a break when they need to.

15. Think about and inform the mediator about what, if any, more specific and personal principles not listed above that they may want added to the list.

These principles are aspirational and should be openly acknowledged as such with the parties, given that they do not in themselves offer a panacea to preventing the expression of natural emotions associated with disputes.

Clearly the content of this list of principles must be acceptable to all parties involved and should include scope for more potential bespoke and individual additions. Strategically they could be talked through in individual assessment meetings and clients encouraged to take them away, consider them in detail and come to a future meeting with any additional personal principles they might wish to be added.

\section{Social media developments}

Other recent electronic communication options have increasingly featured in reports of conflict escalation, across the range of ADR contexts, in particular, texting, emails and Facebook. Mediators engaging in a range of disputes could provide information to disputants regarding the potential dangers of communicating about their dispute via these innovations. 
As referred to above regarding a list of communication principles by disputants, so too might the use of email offer a similar list for adoption by mutual agreement. Such a list could be adapted from one particular writer:

Email can play a role in how we deal with conflicts. We just need to know when and how to use it wisely. Here are some tips for using email in dealing with conflicts and that are usefully generic across different conflict contexts.

\section{Use emails in conflicts:}

- When there needs to be a record of the interaction.

- When dealing with conflicts where the emotional level is fairly low.

- To have an initial conversation that sets up a phone call, or a meeting to deal with the conflict.

Do not use emails in conflicts:

- When the emotional level is high.

- When the email has gone back and forth with a person more than 3 times. This could mean that the issue is too complex to deal with using only email.

Here are some points to consider when dealing with conflicts through email:

- Don't assume why a person didn't respond to an email or answered your email in a certain manner. Intentions are invisible. Get more information.

- Monitor your emotions. If you feel triggered by what you read, don't write an immediate reply back and hit "send." You may regret it once you calm down, and by then, it's too late.

- Save a draft of your reply. Have someone review your draft, or you read it later after you have cooled off, and then sendit.

- Do not rely on emoticons :) or text speak (btw), to convey emotions.

- Be careful with sarcasm and humour because voice tone is absent and your message could be misinterpreted.

- If the email fills the screen ... pick up the phone. The message is probably too complex to not speak with someone aboutit.

- Be careful with "cc's" and the message they send. This may imply that you are ratting a person out to their boss or colleagues (Swink, 2010: 1- 5) 


\section{Better to BIFF than bash}

Continuing with this theme of adopting conflict reduction principles, such ideas can also deal with texting.

One writer offers helpful advice on these issues that could be discussed in a mentoring role. The following are summary extracts:

Do you need to respond? Much of hostile e-communication does not need a response. Letters from (ex-) spouses, angry neighbours, irritating co- workers, or attorneys do not usually have legal significance ... Often, it is emotional venting aimed at relieving the writer's anxiety. If you respond with similar emotions and hostility, you will simply escalate things without satisfaction, and just get a new piece of hostile mail back. In most cases, you are better off not responding ... If you need to respond, I recommend a BIFF Response: Be Brief, Informative, Friendly and Firm ... BRIEF ... Keep your response brief. This will reduce the chances of a prolonged and angry back and forth. The more you write, the more material the other person has to criticize ... INFORMATIVE The main reason to respond to hostile mail is to correct inaccurate statements which might be seen by others. "Just the facts" is a good idea. Focus on the accurate statements you want to make, not on the inaccurate statements the other person made. ...Avoid negative comments. Avoid sarcasm. Avoid threats. Avoid personal remarks about the other's intelligence, ethics or moral behaviour ... FRIENDLY While you may be tempted to write in anger, you are more likely to achieve your goals by writing in a friendly manner. Consciously thinking about a friendly response will increase your chances of getting a friendly - or neutral response in return ... FIRM in a non-threatening way, clearly tell the other person your information or position on an issue. For example: "That's all I'm going to say on this issue" (Eddy, 2007: 1)

\section{Conclusions and recommendations}

This article has attempted to explore changes in client conflict behaviour that may in part be explained by recent social communication influences and models of how to deal with disputes and interpersonal conflict. It has offered theoretical concepts such as conflict ideologies, together with ideas about the constructive management of emotion and high conflict. In particular, it has explored the extent to which the use of pre-mediation and mentoring meetings can address the nature of the 'deal' openly and frankly, regarding how mediators and clients may agree to work together in mediation.

When a mediator is considering a potentially challenging intervention about a participant's behaviour, it is likely to be more readily accepted if framed as an invitation. For example, a mediator may say: "Is it OK if I tell you what I have noticed about how you communicate, and how I think that may be creating some potential problems in what you are trying to do here?" Whether or not the challenge is well received, it is likely that the invitation approach will reduce resistance. Clients can also be invited to reject, disagree with or modify the challenge. Such challenges must be grounded in a relationship of mutual 
respect between practitioner and client that will have been earned from the earliest communication during the engaging stages of contact.

Challenging interventions must be rooted in a mediator hypothesis, based on objective, observed behaviour and communication patterns, not in some abstract and/or theoretical assumption. Such challenge should also, ideally, include ideas as to how any unhelpful communications can be improved on and/or reframed. Challenges are often best preceded by questions as to how the parties feel the meeting is progressing - what we might describe as 'process auditing'. Clients can also be invited to comment on how it feels emotionally when either of them communicates in a particular manner or style. 


\section{References}

Burrell, I. Jeremy Kyle: Judge, jury and exploiter? Independent online Friday 5 April 2013. Sourced 5 April 2013: http://www.independent.co.uk/news/people/profiles/jeremy-kyle-judge-jury- and-exploiter8562459.html.

Eddy, B. (2007) How To Give A BIFF Response. Sourced August 2016 at www.highconflictinstitute.com/articles/mediation

Eddy, B. (2013) When Story Telling Hurts Conflict Resolution: Some Tips for Dispute Resolver. Sourced August 2016 at www.highconflictinstitute.com/articles/mediation

Folger, J. and T. Jones, (1994) New Directions in Mediation Communication Research and Perspectives. London: Sage.

LeBaron, M. and V. Pillay (2006) Conflict Across Cultures, Boston: Intercultural Press.

Maiese, M. (2005) "Emotions Beyond Intractability", in Burgess G. and Burgess

H. (eds.), Conflict Research Consortium, University of Colorado. Accessible on- line <.org/essay/emotion>http://www.beyondHYPERLINK "http://www.beyond/" intractability

Swink, D. (2010) Managing Conflicts With Email: Why It's So Tempting. Dealing with conflict: Can't I just send an email? Posted Jan 14, 2010 Accessed on Google Sept 2016 at https://www.psychologytoday.com/comment/84293.

Tannen, D. (1998) The Argument Culture Changing the Way We Argue, London, Virago.

Winslade, J. and G. Monk (2001) Narrative Mediation - A New Approach to Conflict Resolution. New York, Random House.

\section{Biography}

Tony Whatling, M.Sc. CQSW MCOM, has over 35 years' experience as a family mediator, consultant and trainer. Prior to self-employment 25 years ago he was for 10 years' head of the department of social work education at Anglia Ruskin University Cambridge. He has trained hundreds of mediators throughout UK in Family, Community, Health Care Complaints, Victim Offender and Workplace mediation contexts, and over 1200 Muslim family mediators in 15 countries worldwide - mostly in South East Asia, Middle East, (including Syria and Afghanistan), East Africa, UK, USA and Canada, He has presented several papers and workshops at international conferences, published over 25 articles, is a founder member of the Practice Standards sub-committee and a former governor of the College of Mediators. His book, 'Mediation Skills and Strategies

- A Practical Guide' (April 2012), is also now published in Spanish. 